\title{
Design and Manufacture of Hob Mills for the Formation of Straight Slots Using the Principles of Screw Backing
}

\author{
V. Istotskiy \\ LLC SPC "RIT-Engineering" \\ Chehov, Moscow Region, 142300, Russia \\ Corresponding author: v_ist@mail.ru \\ V. Protasev \\ Tula State University \\ Tula, 300600, Russia
}

(Received November 20, 2018; Accepted May 4, 2019)

\begin{abstract}
The article shows the possibility of designing and manufacturing using multi-coordinate grinding and sharpening machines with CNC for workable worm mills for machining straight-slotted slots. Screw backing provides the necessary values of the rear side corners, and the ability of CNC machines to achieve the required accuracy and manufacturability of the tool. The lack of such tools consists in the increase of the diametrical sizes in comparison with the classically used ones. A positive effect when using the principles of screw backlash is the shaping of the cutting edges of the teeth in a checkerboard pattern, which significantly reduces the cutting forces. The use of techno-logical 3D models as a result of the design allows, at the design stage, to evaluate the arising design flaws and to make the necessary corrective actions into the initial data of the tool.
\end{abstract}

Keywords- Hob cutter, Tool-grinding machines with CNC, Screw backing, Technological 3D model.

\section{Introduction}

Hob cutters are multi-blade cutting tools of rack-and-pinion type, working by the method of rolling, and used for high-performance process of cutting the teeth of gears, splined joints, etc. They are made on the basis of a hob, in which, for the formation of cutting edges, chip grooves are cut, forming the front surface in the form of a rack. The back surfaces of the teeth are formed by the backing, which is necessary for the tool to flow along the front surface and to provide the necessary gaps between the back surfaces and the treated surface.

The widespread use of worm milling cutters in modern engineering is due to the advent of CNC milling machines and specialized devices for CNC lathes for machining surfaces of gear wheels, splined shafts and periodic profiles for various purposes.

The use of worm milling cutters, especially carbide, dramatically improves the performance of gear milling operations and the tool durability period.

The technological disadvantage of the worm milling design is the teeth grinding operation - it is dynamically unbalanced because it uses reciprocating working cycles, grinding wheels of small diametrical dimensions, which affects their durability and, as a consequence, a possible reduction in accuracy from-d.

Screw backing does not have these drawbacks, but it requires the use of design solutions that 
International Journal of Mathematical, Engineering and Management Sciences

Vol. 4, No. 4, 936-945, 2019

https://dx.doi.org/10.33889/IJMEMS.2019.4.4-074

allow the side surfaces of the teeth to be processed according to the regular grinding scheme of the screw surfaces of the right and left directions.

Such processing can be performed on universal thread grinding machines, and in the case of using similar CNC equipment, the efficiency of the process increases several times.

\section{Study of Literature}

Hob "straight-sided" cutters (by GOST 8027) are applied for processing splined shafts with straight-sided profile. These tools can provide the necessary productivity and accuracy by using the roll motion, but according to the work (Inozemtsev, 1984) they have unacceptably small values of the working rear angles $\alpha_{\mathrm{s}}$ on the side cutting edges.

Values $\alpha_{\mathrm{s}}$ are calculated according to the equation (1)

$\operatorname{tg} \alpha_{s}=\operatorname{tg} \alpha_{b} \cdot \frac{r_{\max }}{r_{i}} \cdot \operatorname{Sin} \sigma$

where $\alpha_{b}$ - the angle at the top of the teeth, provided by the backing; $\sigma$ - profile angle at the considered point of the side cutting edge; $r_{\max }, r_{i}$ - radiuses of the initial and maximum circumference (respectively) at the considered point on the tooth profile.

For example, if $\alpha_{b}=12^{\circ}, r_{\max }=65 \mathrm{~mm}, r_{i}=60 \mathrm{~mm}, \sigma=2^{\circ}$, that $\alpha_{s}=0.4^{\circ}$. Such a tool is inoperable, and therefore structural and technological changes are needed to ensure its performance (Kolesnikova et al., 2018; Pshenay-Severin et al., 2018).

\section{Problem Statement}

In Protas'ev et al. (2003) proposed a method for relieving work of side surfaces of the teeth using a multistart helical surface with a constant pitch of the right and left directions, and the corresponding design of hob (Indeitsev et al., 2018). However, this work does not give an example of calculating the "straight-sided" hob cutter, in which the lateral rear angles $\alpha$ s have the same values on both sides of the tooth (Repin and Valdman, 2018).

In order to eliminate the above drawback (lack of lateral rear corners), which reduces the efficiency of the use of hob cutters, consider the design scheme (Figure 1) to determine the main design parameters of the hob with the use of a spiral relief and are used in their manufacture on tool grinding machines with CNC. 
International Journal of Mathematical, Engineering and Management Sciences

Vol. 4, No. 4, 936-945, 2019

https://dx.doi.org/10.33889/IJMEMS.2019.4.4-074
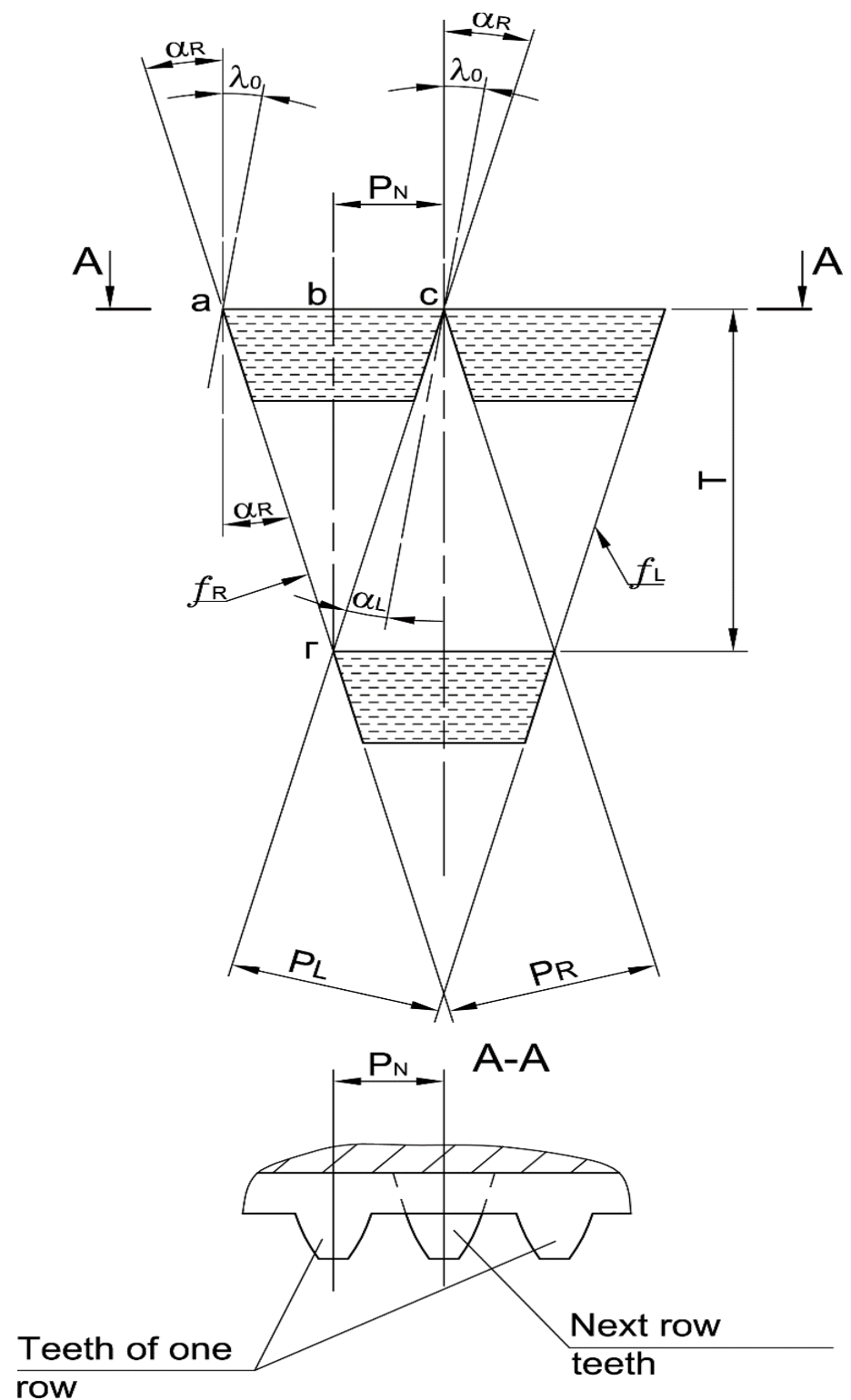

Figure 1. Determination of design parameters of hobs manufactured screw backing

\section{Design "straight-sided" Hob Cutters Using the Relieving Work}

Figure 1 shows the sweep of the hob cutter on the main circle, where the angle of inclination of the main hob $\lambda_{0}$ is visible in full size. The peculiarity of these mills is the possibility of grinding the rear side surfaces of the teeth according to the scheme of treatment of the right and left of multistart helical surface with guide curves $f_{R}$ when grinding the rear surfaces of the right and $f_{L}-$ when grinding left. 
International Journal of Mathematical, Engineering and Management Sciences

Vol. 4, No. 4, 936-945, 2019

https://dx.doi.org/10.33889/IJMEMS.2019.4.4-074

At the same time removed all restrictions from the diametrical dimensions of the second order tools - grinding wheels, since it is not used, the reciprocating motion of relieving work (Rudskoy et al., 2016, 2018).

The objective of the calculation is that it is necessary to calculate the values of, $P_{R}$ and $P_{L}$ of the right and left helical surfaces, the number of their entries $i_{R}$ and $i_{L}$ in which the rear corners $\alpha_{5}$ on the sides of the teeth are equal to each other and their values for efficient chip removal (Getsov et al., 2017; Klochkov, 2018; Klochkov et al., 2018).

Figure 2 shows the complete (corresponding to one revolution) reamer cutters with screw backing. A priori it is accepted that the cutter has 11 teeth, staggered, the angle of rise of the main hob $\lambda_{0}$, the steps of the right and left directions $P_{R}$ and $P_{L}$ and guide lines $f_{R}$ and $f_{L}\left(Z_{T}=11, i_{R}=6\right.$, $i_{L}=5$ ) (Zobacheva et.al., 2017; Borovkov et.al., 2018).

The fragment on the right side shows the construction, allowing to determine the relationship between the normal step $P_{N}$ and the axial step $P_{0}$. It follows from the Figure 2 that the main step of the hob cutter is equal to $P_{N}$. This value is known from the initial information about the profile of the work piece.

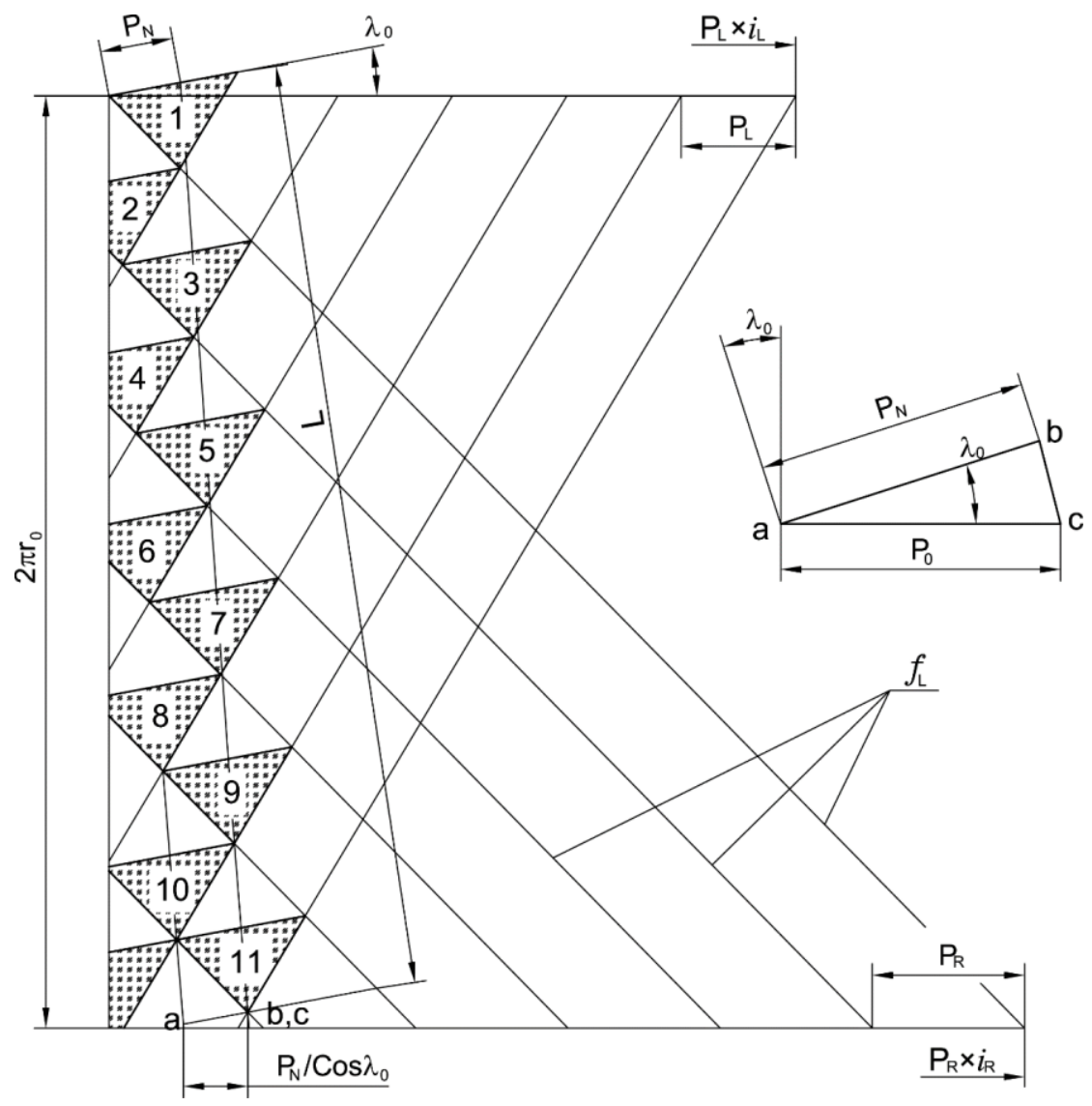

Figure 2. Determination of the number of teeth of the cutter and of the relationship of normal $P_{N}$ and $P_{0}$ is the axial steps 
International Journal of Mathematical, Engineering and Management Sciences

Vol. 4, No. 4, 936-945, 2019

https://dx.doi.org/10.33889/IJMEMS.2019.4.4-074

Here is an example of the calculation of the hob cutter, accompanied by its numerical data:

Take a valid value of the lateral posterior angles $\alpha_{s}=12^{\circ}$ main step $P_{N}=10 \mathrm{~mm}$.

$T=\frac{P_{N}}{\operatorname{tg} \alpha_{s}}=\frac{10}{\operatorname{tg} 12}=47.0463 \mathrm{~mm}$

We define, using Figure 2, the radius of the main circle $\mathrm{r}_{0}$, assuming that the cutter has 11 teeth.

To do this, first determine the length of the segment required to accommodate eleven teeth

$L=T \cdot 11=47.0463 \cdot 11=517.5093 \mathrm{~mm}$

When the received data

$r_{0}=\frac{L}{2 \cdot \pi}=\frac{517.5093}{6.2832}=82.3641 \mathrm{~mm}$

Calculate the angle of rise of the main hob. According to the construction of the fragment in Figure 2, we obtain

$\operatorname{Sin} \lambda_{0}=\frac{P_{N}}{2 \cdot \pi \cdot r_{0}}=\frac{10}{6.2832 \cdot 82.3641}=0.01932$

Respectively $\lambda_{0}=1.1072^{\circ}$.

Determine the values of the right and left steps forming the side rear surfaces and the number of their inputs. According to the construction of Figure 1 (see point a, b) we have

$\alpha_{R}=\lambda_{0}+\alpha_{s}$

$\alpha_{L}=\alpha_{s}-\lambda_{0}$

In our case

$\alpha_{R}=\lambda_{0}+\alpha_{s}=1.1072+12=13.1072^{\circ}$,

$\alpha_{L}=\alpha_{s}-\lambda_{0}=12-1.1072=10.8928^{\circ}$.

From other side

$\operatorname{tg} \alpha_{R}=\frac{P_{R} \cdot i_{R}}{2 \cdot \pi \cdot r_{0}}$,

where $P_{R}-$ step of right screw surfaces; $i_{R}-$ the number of inputs of the right screw surfaces.

Since the right single-pass $\left(Z_{0}=1\right)$ hob cutter is designed

$i_{R}+i_{L}=Z_{T}$

and 
International Journal of Mathematical, Engineering and Management Sciences

Vol. 4, No. 4, 936-945, 2019

https://dx.doi.org/10.33889/IJMEMS.2019.4.4-074

$$
Z_{0}=i_{R}-i_{L}
$$

At the values accepted earlier $Z_{T}=11, i_{R}=6$ and $i_{L}=5$, deciding (8) on $P_{R}$ get:

$$
P_{R}=\frac{\operatorname{tg} \alpha_{R} \cdot 2 \cdot \pi \cdot r_{0}}{i_{R}}=\frac{\operatorname{tg} 13.1072 \cdot 6.2832 \cdot 82.3641}{6}=20.0828 \mathrm{~mm}
$$

Similarly, we calculate the value of the left step

$$
P_{L}=\frac{\operatorname{tg} \alpha_{L} \cdot 2 \cdot \pi \cdot r_{0}}{i_{L}}=\frac{\operatorname{tg} 10.8928 \cdot 6.2832 \cdot 82.3641}{5}=19.9178 \mathrm{~mm}
$$

The construction of Figure 1 allows us to obtain an equation for determining the angle $\lambda_{0}$, differently from the dependence (5).

$\lambda_{0}=\frac{\alpha_{R}-\alpha_{L}}{2}=\frac{13.1072-10.8928}{2}=1.1072$

The resulting value is the same as the value defined by the equation (5). Comparison of the results can be used to verify the correctness of the calculations. Such a small angle of rise of the main hob allows you to ignore it and make a straight-toothed tool, thus ensuring maximum simplicity of its regrinding on the front surface (Kudinova et al., 2016).

The problems of calculating the shape-forming profiles of the teeth of hob mills, necessary to ensure the profile of the slots with sufficient completeness are considered in (Lashnev and Yulikov, 1975), therefore, this article is not considered.

\section{Analysis of the Results}

After analyzing the above calculation algorithm, it is worth noting that the disadvantage of hob cutters made with the use of relieving work is an increase (approximately 1.8...2 times in comparison with (by GOST 8027-86)) of their diametrical dimensions while maintaining the same number of teeth $Z_{T}$.

At the same diametrical values, the back angles $\alpha$ s increase to $25 \ldots 30^{\circ}$, which is unacceptable in the processing of metals, but can be effectively used in the processing of non-metallic materials.

A positive feature of the mills is the location of the teeth in staggered order. Figure 1 and section A-A confirm this possibility (Guchinsky and Petinov, 2016).

When processing small profiles, this can significantly increase the size of the teeth and, as a consequence, their strength and manufacturability of the tool, but in the case of processing large profiles, the considered feature becomes a significant drawback (Ziniakov et al., 2016). Therefore, the area of use of such phrases translated into involute engagement-wheels with modules from 0.5 to $1.5 \mathrm{~mm}$.

For forming the cutting tool with the implementation of the above algorithm it is expedient to use modern tool grinding machines, such as VZ-452F4 ideal for tools with screw backing. In (Istotskiy and Protas'ev, 2006; Protas'ev and Istotskiy, 2011; Istotskiy and Protasev, 2017) provides the features of the design, construction and operation of tools, including screw backing, 
International Journal of Mathematical, Engineering and Management Sciences

Vol. 4, No. 4, 936-945, 2019

https://dx.doi.org/10.33889/IJMEMS.2019.4.4-074

and the above information indicates the expansion of sustainable exploitation tools with screw backing. Modern tool production at the stage of its preparation is unthinkable without the formation of a technological 3D model (Ni, 2006; Istotskiy and Protas'ev, 2007; Pham and Ko, 2010), obtained using a virtual analogue of the grinding and grinding machine, where it is formed using the principles of Boolean algebra (Abushawashi et al., 2017). The result of this simulation using the calculations performed above is shown in Figure 3.

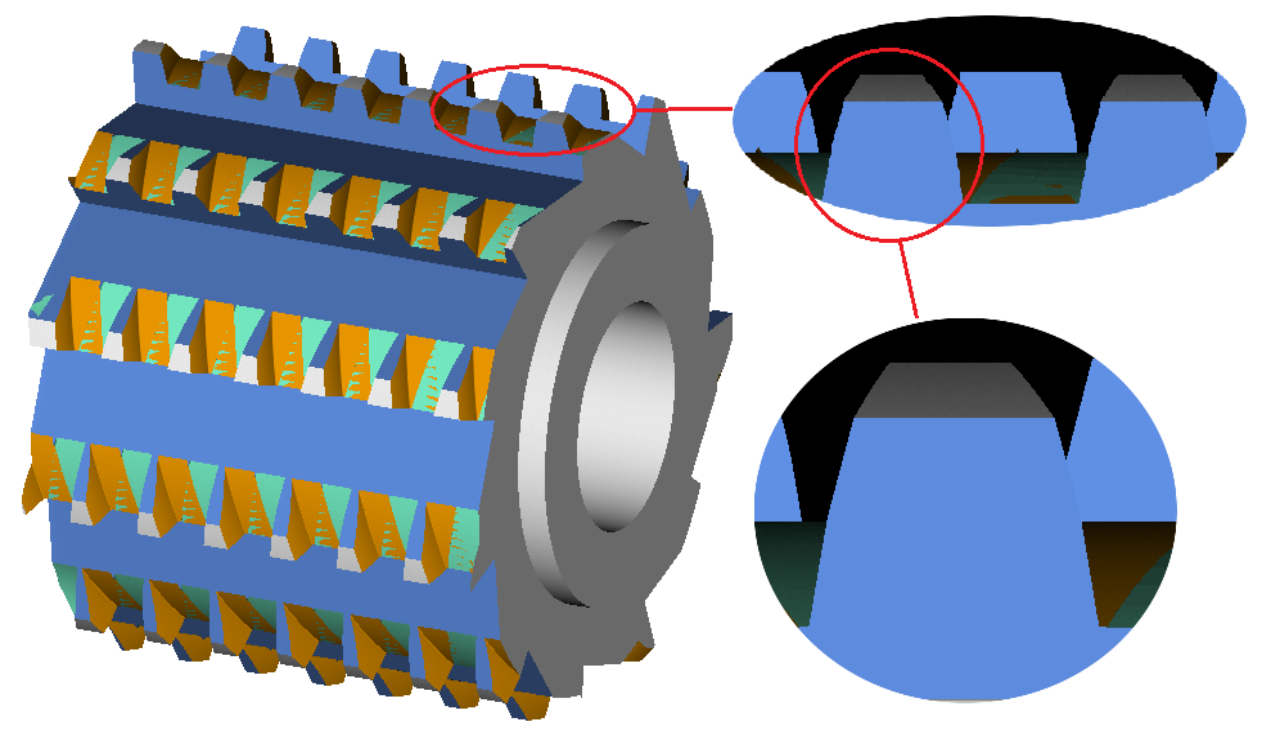

Figure 3. Technological 3D model of hob, designed with the principles of the relieving work (relieving work on cylinder not shown).

The principle of the screw backing of at least 10 years is successfully used by specialists of the company "RIT-Engineering" in the manufacture of axial threading tools, forming chip-brake grooving tools for machining of difficult to machine materials, hobs (Shymchenko et al., 2016; Solopchenko, 2016). In all cases, there is an increase in tool life, improves the dynamics of the process of removing the allowance and reduces the roughness of the treated surface.

\section{Conclusion}

Application of the method of design "straight-sided" hobs with the principles of the relieving work provides the necessary values of the rear side of the angles in the range $\mathrm{m}=0.5 \ldots 1.5$ (with translation of involute gearing), and the possibility of tool grinding CNC machines ensure their production in a single clamping of the workpiece, which ensures improved quality and reduced labor costs on the production of such high-tech products hob.

The screw relieving work can effectively be used not only by production of worm mills, but also at production thread-milling attachment, "corn" mills, special vertical drills, including for formation of shaped openings. 
International Journal of Mathematical, Engineering and Management Sciences

Vol. 4, No. 4, 936-945, 2019

https://dx.doi.org/10.33889/IJMEMS.2019.4.4-074

Screw backing can be effectively used not only in the manufacture of worm mills, but also in the manufacture of thread mills, "corn" mills, special countersinks, including for the formation of shaped holes.

In the manufacture of fine-cut mills for the production of clockwork mechanisms, in which cycloidal gearing is used, the teeth of which have small values of profile angles and are close in shape to rectangular slots, applying the principles of screw backlash when designing tools is the best solution.

Using the designed tool as a tool for controlling technological 3D models makes it possible, at the preproduction stage, to optimize its parameters for real process equipment, while minimizing costs and design flaws.

\section{Conflict of Interest}

The authors confirm that there is no conflict of interest to declare for this publication.

\section{Acknowledgements}

The paper is based on the research carried out with the financial support of the grant of the Russian Science Foundation (Project No. 14-38-00009, the program-targeted management of the Russian Arctic zone development). Peter the Great St. Petersburg Polytechnic University.

\section{References}

Abushawashi, Y., Xiao, X., \& Astakhov, V. (2017). Practical applications of the "energy-triaxiality" state relationship in metal cutting. Machining Science and Technology, 21(1), 1-18.

Borovkov, A.I., Mamchits, D.V., Nemov, A.S., \& Novokshenov, A.D. (2018). Problems of modeling and optimization of variable-hardness panels and structures made of layered composites. Mechanics of Solids, 53(1), 93-100.

Getsov, L.B., Semenov, A.S., \& Ignatovich, I.A. (2017). Thermal fatigue analysis of turbine discs on the base of deformation criterion. International Journal of Fatigue, 97, 88-97.

Guchinsky, R., \& Petinov, S. (2016). Numerical modeling of the surface fatigue crack propagation including the closure effect. International Journal for Computational Methods in Engineering Science and Mechanics, 17(1), 1-6.

Indeitsev, D.A., Porubov, A.V., Skubov, D.Y., Lukin, A.V., Popov, I.A., \& Vavilov, D.S. (2018). On the influence of the microstructure on the stress-strain state of material. Materials Physics and Mechanics, $35(1), 66-70$.

Inozemtsev, G.G. (1984). Design of metal-cutting tools: Studies. Manual for Universities in the specialty "Technology, metal-cutting machines and tools" (Vol. 1).M. Machine building.

Istotskiy, V., \& Protasev, V. (2017). Increasing the level of technical perfection technology manufacture of cutting tools. Norwegian Journal of development of the International Science, 11(1), 61-70.

Istotskiy, V.V., \& Protas'ev, V.B. (2006). The principles of the modern design of the cutting tools shaped with the features of their manufacturing on grinding machines. News TSU, 102-107. 
International Journal of Mathematical, Engineering and Management Sciences

Vol. 4, No. 4, 936-945, 2019

https://dx.doi.org/10.33889/IJMEMS.2019.4.4-074

Istotskiy, V.V., \& Protas'ev, V.B. (2007, January 29-30). Design of the cutting tools shaped with the use of virtual analogues tool grinding CNC machines based on Boolean algebra. News TSU. (Vol.2). In Proceedings of the International scientific. - techn. conf. "Problems of shaping of parts in machining", dedicated 90th anniversary of S. I. Lashnev.

Klochkov, Y. (2017, December). Conflicts between quality management methods. In 2017 International Conference on Infocom Technologies and Unmanned Systems (Trends and Future Directions)(ICTUS) (pp. 34-36). IEEE.

Klochkov, Y., Gazizulina, A., Golovin, N., Glushkova, A., \& Zh, S. (2018, December). Information modelbased forecasting of technological process state. In 2017 International Conference on Infocom Technologies and Unmanned Systems (Trends and Future Directions)(ICTUS) (pp. 709-712). IEEE.

Kolesnikova, A.L., Gutkin, M.Y., \& Romanov, A.E. (2018). Analytical elastic models of finite cylindrical and truncated spherical inclusions. International Journal of Solids and Structures, 143, 59-72.

Kudinova, N.R., Polyanskiy, V.A., Polyanskiy, A.M., \& Yakovlev, Y.A. (2016, October). Contribution of surface tension energy during plastic deformation of nanomaterials. In Doklady Physics (Vol. 61, No. 10, pp. 514-516). Pleiades Publishing.

Lashnev, S.I., \& Yulikov, M.I. (1975). Calculation and design of metal-cutting tools using computers. M. Machine building.

Ni, G.G. (2006). Application on technology of CAD/CAM for the design and manufacturing of ball end cutter [D].Master thesis of Tianjin University of Technology (Vol. 6).

Pham, T.T., \& Ko, S.L. (2010). A manufacturing model of an end mill using a five-axis CNC grinding machine. The International Journal of Advanced Manufacturing Technology, 48(5-8), 461-472.

Protas'ev, V.B., \& Istotskiy, V.V. (2011). Design of shaped tools produced using tool-grinding machines with CNC. In Moscow: INFRA-M, 2011, "Scientific Thought".

Protas'ev, V.B., Stepanov, S., Yu, \& Ushakov, M.V. (2003). The progressive structure of the relief cutting tools. Edited by Y. S. Stepanov. Series "Toolmaker's Library", M.: Machine building.

Pshenay-Severin, D.A., Ivanov, Y.V., Burkov, A.T., Novikov, S.V., Zaitsev, V.K., \& Reith, H. (2018). Electronic Structure and Thermoelectric Properties of Transition Metal Monosilicides. Journal of Electronic Materials, 47(6), 3277-3281.

Repin, S., \& Valdman, J. (2018). Error identities for variational problems with obstacles. ZAMM-Journal of Applied Mathematics and Mechanics/Zeitschrift für Angewandte Mathematik und Mechanik, 98(4), 635-658.

Rudskoi, A.I., Bogatov, A.A., Nukhov, D.S., \& Tolkushkin, A.O. (2018). On the development of the new technology of severe plastic deformation in metal forming. Materials Physics and Mechanics, 38(1), 76-81.

Rudskoy, A.I., Bogatov, A.A., Nukhov, D.S., \& Tolkushkin, A.O. (2018). New method of severe plastic deformation of metals. Metal Science and Heat Treatment, 60(1-2), 3-6.

Rudskoy, A.I., Kodzhaspirov, G.E., Kliber, J., \& Apostolopoulos, C. (2016). Advanced metallic materials and processes. Materials Physics \& Mechanics, 25(1), 1-8

Shymchenko, A.V., Tereshchenko, V.V., Ryabov, Y.A., Salkutsan, S.V., \& Borovkov, A.I. (2017). Review of the computational approaches to advanced materials simulation in accordance with modern advanced manufacturing trends. Materials Physics and Mechanics, 32(3), 328-352.

Solopchenko, G.N. (2016). Fields of effective application of statistical methods of processing the results of repeated measurements. Measurement Techniques, 59(5), 476-484. 
International Journal of Mathematical, Engineering and Management Sciences

Vol. 4, No. 4, 936-945, 2019

https://dx.doi.org/10.33889/IJMEMS.2019.4.4-074

Ziniakov, V.Y., Gorodetskiy, A.E., \& Tarasova, I.L. (2016). Control of vitality and reliability analysis. Studies in Systems, Decision and Control, 49, 193-204 doi:10.1007/978-3-319-27547-5_18.

Ziniakov, V.Y., Gorodetskiy, A.E., \& Tarasova, I.L. (2016). System failure probability modelling. Studies in Systems, Decision and Control, 49, 205-215. doi:10.1007/978-3-319-27547-5_19.

Zobacheva, A.Y., Nemov, A.S., Borovkov, A.I., Novokshenov, A.D., Khovaiko, M.V., \& Ermolenko, N. A. (2017). Design and simulation of additive manufactured structures of three-component composite material. Materials Physics and Mechanics, 34(1), 51-58. 